\title{
Pulmonary Manifestations of Systemic Diseases
}

\author{
Cornelia Schaefer-Prokop and Brett M. Elicker
}

\section{Learning Objectives}

- Discuss the typical lung manifestations of systemic diseases including sarcoidosis, connective tissue disease, and vasculitis.

- Understand the role of radiology, and in particular computed tomography, in the diagnosis and management of patients with systemic diseases.

- Identify typical CT findings and patterns of systemic diseases and their differential diagnoses.

\subsection{Introduction}

The diagnosis of systemic diseases involves an analysis of their characteristic clinical manifestations in different organ systems. Clinical features are often correlated with serologic abnormalities, radiologic findings, and, in some cases, histopathology. Systemic diseases may affect a variety of different compartments of the thorax including the lungs, pleura, pericardium, lymph nodes, vessels, and heart. This discussion will focus on their lung manifestations; however reference will also be made to their extrapulmonary manifestations, as these often provide important clues to diagnosis. The prevalence of lung involvement varies: while it is a predominant feature of certain systemic diseases, such as sarcoidosis or granulomatosis with polyangiitis (GPA, formerly Wegener's granulomatosis), it is only rarely present in others such as Henoch-Schönlein purpura.

C. Schaefer-Prokop $(\bowtie)$

Department of Radiology, Meander Medical Centre, Amersfoort, Netherlands

Department of Radiology, Radboud University, Nijmegen, Netherlands

B. M. Elicker $(\bowtie)$

Department of Radiology and Biomedical Imaging, University of

California, San Francisco, CA, USA

e-mail: brett.elicker@ucsf.edu
The roles of imaging in systemic diseases vary somewhat depending upon the specific disorder. Radiology, and in particular computed tomography (CT), may be important in establishing a diagnosis. Sarcoidosis, as an example, is a disease for which typical CT findings are often critical in establishing an accurate diagnosis. Connective tissue disease, on the other hand, is often diagnosed primarily using clinical and serologic findings; thus imaging has a somewhat limited role in diagnosis. However, it is also seen in clinical practice that findings on CT such as signs of lung fibrosis (especially the NSIP pattern) represent the trigger for diagnostic workup for the presence of an underlying systemic disease. When imaging doesn't play a major role in diagnosis, it is still important in establishing the presence and pattern of lung disease as well as disease extent, all of which have an impact on treatment decisions. Imaging also has important roles in serial follow-up of lung abnormalities over time and evaluating patients with worsening or acute symptoms.

In the following we will focus on the more common systemic disorders that develop pulmonary abnormalities such as sarcoidosis, connective tissue diseases, and vasculitis. While a comprehensive review of the lung manifestations of all systemic diseases is not possible, a few selected rare disorders will also be discussed including inflammatory bowel disease, amyloidosis, Erdheim-Chester disease, and IgG4related sclerosing disease.

\subsection{Sarcoidosis}

Sarcoidosis is a systemic disorder of unknown origin. A genetic predisposition to sarcoidosis is indicated by observations of familial clustering. Sarcoidosis is characterized by noncaseating epithelioid cell granulomas in multiple organs, but morbidity and mortality are closely related to pulmonary manifestations occurring in $>90 \%$ of patients [1]. The CT appearance of pulmonary sarcoidosis varies greatly [2] and is known to masquerade many other diffuse infiltrative lung 
diseases; conversely several diseases can resemble classical sarcoidosis.

The histology of pulmonary sarcoidosis consists of noncaseating granulomas with a rim of lymphocytes and fibroblasts in a perilymphatic distribution, which may resolve or cause fibrosis. The disease may occur at any age but mostly affects individuals between 20 and 40 years of age and only rarely occurs in over 65 years of age. The prognosis is mostly good with disease resolution often occurring in $<2$ years and mortality between $1 \%$ and $5 \%$.

The three criteria for diagnosis are (1) typical clinical and radiological manifestations, (2) the presence of noncaseating granulomas, and (3) exclusion of alternative diseases. The respective weight of each criterion varies with individual presentation: while in some patients with suspected sarcoidosis typical findings on a chest radiograph can be sufficient in the correct context (i.e., uveitis, erythema nodosum), in other patients a classic nodular pattern on CT is necessary to establish diagnosis, and last there is a subgroup of patients in which controversial or nonspecific clinical and radiological findings make histological proof necessary (e.g., biopsy of skin lesions, endobronchial ultrasound-guided transbronchial needle aspiration for mediastinal or hilar lymphadenopathy).

Pulmonary findings on CT include small, well-defined nodules in a characteristic perilymphatic distribution in relation to the subpleural surface, adjacent to the major fissures, along thickened interlobular septa, and adjacent to vessels in the lobular core [3]. The nodules may be evenly distributed throughout both lungs with predominance of the upper and middle lung zones; however they may be also clustered in the perihilar and peribronchovascular regions with relative sparing of the lung periphery, or they may be grouped in small areas. Confluence of granulomas results in larger nodules (1-4 cm, nodular sarcoid, galaxy sign) or illdefined opacities (ground glass or consolidations, up to $10 \mathrm{~cm}$, alveolar sarcoidosis).

Lymphadenopathy is typically seen in a subcarinal, right paratracheal, aortopulmonary, and symmetric hilar distribution. In advanced stage CT calcifications are seen in lymph nodes with an eggshell or amorphous cloudlike ("icing sugar") pattern.

Up to $25 \%$ of patients develop irreversible pulmonary fibrosis with architectural distortion, displacement of the interlobular septa, traction bronchiectasis, honeycombing, and bullae (stage IV). Conglomerate masses, mostly in a perihilar location, represent areas of fibrosis with characteristic traction bronchiectasis. Volume loss of the upper lobes is associated with hilar retraction and septal displacement.

Airway abnormalities include airway compression caused by surrounding lymphadenopathy and traction bronchiectasis caused by surrounding fibrosis. Granulomas within the bronchial walls cause irregular bronchial wall thickening with narrowing of the large and small airways. Involvement of the small airways causes lobular air trapping more easily identifiable on expiratory CT scans.

Sarcoidosis may present with very characteristic HRCT features allowing for a secure diagnosis and obviating further invasive procedures. However, sarcoidosis is also known to present with less typical features (Table 11.1).

Especially in advanced disease with fibrosis, the differential diagnosis between sarcoidosis and other fibrosing diseases can be challenging. Table 11.2 summarizes imaging findings helpful for differentiating diseases.

Complications include the development of an aspergilloma and pulmonary hypertension.

Mycetomas are a typical complication of stage IV sarcoidosis: they present with a soft tissue mass located in a preexisting cavity in patients with fibrotic sarcoidosis. Lifethreatening hemoptysis may require immediate interventional therapy (embolization of bronchial arteries).

Pulmonary hypertension occurs in patients with end-stage fibrosis but may be also caused by mediastinal fibrosis, extrinsic compression of the pulmonary arteries by lymphadenopathy, or intrinsic sarcoid vasculopathy including features of pulmonary veno-occlusive disease.

Staging based on chest radiography (Siltzbach classification, Table 11.3) was developed decades ago, before the broad use of CT; it is purely descriptive and does not indicate disease activity.

FDG-PET can be used to accurately assess inflammatory activity, for example, in patients with persistent disabling symptoms without serological inflammatory activity [4]. PET has also been described to be helpful to predict pulmonary deterioration at 1 year and to monitor therapy response.

Table 11.1 HRCT manifestations of Sarcoidosis

\begin{tabular}{l|l|}
$\begin{array}{l}\text { Typical features } \\
\text { Lymphadenopathy: }\end{array}$ & $\begin{array}{l}\text { hilar, mediastinal, bilateral symmetric, well } \\
\text { defined } \\
\text { micronodules (2-4 mm), well-defined, } \\
\text { larger coalescing nodules }\end{array}$ \\
\hline Nodules: & $\begin{array}{l}\text { subpleural, interlobular septa, } \\
\text { peribronchovascular }\end{array}$ \\
\hline $\begin{array}{l}\text { Perilymphatic } \\
\text { distribution: }\end{array}$ & $\begin{array}{l}\text { reticular opacities, architectural distortion, } \\
\text { bronchiectasis, volume loss }\end{array}$ \\
\hline pibrosis: & $\begin{array}{l}\text { predominance of upper lobes and perihilar } \\
\text { areas }\end{array}$ \\
\hline $\begin{array}{l}\text { Atypical features } \\
\text { Lymphadenopathy: }\end{array}$ & $\begin{array}{l}\text { unilateral, isolated, in atypical mediastinal } \\
\text { locations }\end{array}$ \\
\hline $\begin{array}{l}\text { Airspace } \\
\text { consolidations: }\end{array}$ & $\begin{array}{l}\text { conglomerate masses, confluent alveolar } \\
\text { opacities (alveolar sarcoidosis) }\end{array}$ \\
\hline $\begin{array}{l}\text { Linear opacities: } \\
\text { interlobular septal thickening } \\
\text { Fibrocystic changes: }\end{array}$ & $\begin{array}{l}\text { cysts, bullae, honeycomb-like opacities, } \\
\text { upper lobe predominance }\end{array}$ \\
\hline $\begin{array}{l}\text { Airway involvement: } \\
\text { atelectasis, mosaic pattern } \\
\text { Pleural disease: }\end{array}$ & effusion, pneumothorax, pleural plaques \\
\hline
\end{tabular}


Table 11.2 Diseases with imaging features that overlap with sarcoidosis

\begin{tabular}{|c|c|c|}
\hline Differential diagnosis & Overlapping finding & Suggestive for sarcoidosis \\
\hline $\begin{array}{l}\text { Lymphangitic } \\
\text { carcinomatosis }\end{array}$ & $\begin{array}{l}\text { - Irregular "beaded" thickening of the interlobular } \\
\text { septa }\end{array}$ & $\begin{array}{l}\text { - Upper lobe predominance } \\
\text { - Absence of pleural effusion } \\
\text { - Less central bronchial cuffing }\end{array}$ \\
\hline Silicosis/pneumoconiosis & $\begin{array}{l}\text { - Pleural pseudoplaques } \\
\text { - Egg shell calcifications of lymph nodes } \\
\text { - Perihilar fibrotic masses }\end{array}$ & $\begin{array}{l}\text { - No calcifications in pseudoplaques, } \\
\text { - Pseudoplaques consist of confluent nodules } \\
\text { - The perihilar fibrotic masses extend directly from the } \\
\text { hilar structures and move posteriorly (volume loss } \\
\text { upper lobe) }\end{array}$ \\
\hline $\begin{array}{l}\text { Chronic EAA/chronic HP } \\
\text { and UIP/IPF }\end{array}$ & $\begin{array}{l}\text { - Honeycombing } \\
\text { - } \text { Traction bronchiectasis } \\
\text { - Lobular distribution of areas with air trapping (in } \\
\text { the presence of obliterative bronchiolitis) and } \\
\text { fibrosis }\end{array}$ & $\begin{array}{l}\text { - UIP pattern predominantly in upper lobes or perihilar } \\
\text { region } \\
\text { - Thickened interlobular septa } \\
\text { - Lymph node calcifications } \\
\text { - Fibrosis and traction bronchiectasis tend to run from } \\
\text { the hilar structures dorsolaterally }\end{array}$ \\
\hline $\begin{array}{l}\text { Lymphoproliferative } \\
\text { disorders }\end{array}$ & - Lymphadenopathy & $\begin{array}{l}\text { - Usually but not always symmetric } \\
\text { - Presence of typical parenchymal findings (caveat: } \\
\text { biopsy may be necessary) }\end{array}$ \\
\hline Chronic beryllium disease & - Nodular pattern & $\begin{array}{l}\text { - Large hilar lymphadenopathy } \\
\text { - No exposure to beryllium } \\
\text { - Other organ involvement }\end{array}$ \\
\hline Tuberculosis & $\begin{array}{l}\text { Nodular pattern } \\
\text { (normally random versus perilymphatic nodules; } \\
\text { however, sarcoidosis may occasionally show a } \\
\text { random pattern) }\end{array}$ & $\begin{array}{l}\text { Egg shell or disperse calcifications as opposed to } \\
\text { rough TB calcifications } \\
\text { - Symmetric calcifications (in Tb frequently } \\
\text { asymmetric) } \\
\text { - Clinical symptoms of acute infection in patients with } \\
\text { military TB }\end{array}$ \\
\hline $\begin{array}{l}\text { Common variable immune } \\
\text { deficiency (CVID) }\end{array}$ & $\begin{array}{l}\text { - Nodules in perilymphatic distribution } \\
\text { - Ill-defined nodules in mid-lower predominance }\end{array}$ & $\begin{array}{l}\text { - Different clinical histories (in CVID recurrent } \\
\text { bacterial infection) } \\
\text { - Different histological features }\end{array}$ \\
\hline
\end{tabular}

EAA, exogenic allergic alveolitis; HP, hypersensitivity pneumonitis see also Spagnolo P, Sverzellati N, Wells AU, and Hansell D. Eur Radiol 2014;24: 807

Table 11.3 Siltzbach classification of sarcoidosis

\begin{tabular}{|c|c|c|c|}
\hline & CXR findings & Stage at diagnosis & $\begin{array}{l}\text { Spontaneous } \\
\text { remission in }\end{array}$ \\
\hline Stage 0 & $\begin{array}{l}\text { Normal chest } \\
\text { radiograph }\end{array}$ & $5-10 \%$ & \\
\hline Stage 1 & $\begin{array}{l}\text { Bilateral hilar and } \\
\text { paratracheal } \\
\text { lymphadenopathy }\end{array}$ & $50 \%$ & $60-90 \%$ \\
\hline Stage 2 & $\begin{array}{l}\text { Lymphadenopathy and } \\
\text { nodular opacities }\end{array}$ & $25-30 \%$ & $40-70 \%$ \\
\hline Stage 3 & $\begin{array}{l}\text { Nodular opacities } \\
\text { without } \\
\text { lymphadenopathy or } \\
\text { signs of fibrosis }\end{array}$ & $10-12 \%$ & $10-20 \%$ \\
\hline Stage 4 & Fibrosis & $\begin{array}{l}5 \%, \text { in up to } 25 \% \\
\text { progression to } \\
\text { stage } 4 \text { during } \\
\text { course of disease }\end{array}$ & $0 \%$ \\
\hline
\end{tabular}

Inhibition of the physiological myocardial FDG uptake, e.g., by appropriate diets, enables the detection of cardiac sarcoidosis active lesions.

Recently an integrated clinicoradiological staging system [5] has been proposed to identify patients with poor prognosis and at risk for mortality (50\% in 5.5 years): while initial separation between the two prognostic groups was done by

\subsection{Connective Tissue Disease}

applying a weighted combination of lung function parameters, further separation was yielded if extent of fibrosis on CT exceeded $20 \%$ and/or a pathological diameter ratio of the main pulmonary and ascending aorta $(>1)$ was seen.

\section{Key Point}

- The typical CT findings of sarcoidosis include (1) perilymphatic nodules located predominantly in the peribronchovascular and subpleural interstitium, (2) symmetric bilateral hilar and mediastinal lymphadenopathy, and (3) upper lobe and peribronchovascular fibrosis.

Connective tissue diseases (CTDs) are characterized primary upon clinical grounds, namely, typical clinical complaints and physical examination findings. The presence of specific autoantibodies also assists in making a specific diagnosis. While imaging has an important role in determining the presence and pattern of lung disease present, its role in diagnosis is limited. It is important to note, 
however, that lung abnormalities may precede the other clinical manifestations, sometimes by more than 5 years. In these cases, imaging may suggest the possibility of CTD, even when a patient doesn't meet the criteria for a specific one (see interstitial pneumonia with autoimmune features below).

CTD can affect different compartments of the thorax including the lung, pleura, pericardium, lymphatics, vasculature, and heart. Commonly, more than one compartment is involved. Involvement of the respiratory system is common in CTDs and results in significant morbidity and mortality. Many of the lung manifestations of CTD [6] are similar to the idiopathic interstitial pneumonias and can be classified using the same system [7].

Lung biopsy is rarely obtained in patients with a defined CTD. For this reason, high-resolution CT often determines the predominant pattern of injury present. This pattern is important in determining treatment and prognosis. While many possible patterns of injury are associated with each specific CTD [8], certain patterns are more common than others (Table 11.4). For instance, organizing pneumonia is most commonly seen in association with polymyositis or dermatomyositis. It is also important to note that more than one pattern of injury may be present in the same patient.

Table 11.4 Different connective tissue diseases and their primary pulmonary manifestations

\begin{tabular}{|c|c|c|}
\hline $\begin{array}{l}\text { Connective } \\
\text { tissue disease }\end{array}$ & Most common pattern(s) & $\begin{array}{l}\text { Less common } \\
\text { pattern(s) }\end{array}$ \\
\hline $\begin{array}{l}\text { Rheumatoid } \\
\text { arthritis }\end{array}$ & $\begin{array}{l}\text { - Usual interstitial } \\
\text { pneumonia } \\
\text { - Nonspecific interstitial } \\
\text { pneumonia }\end{array}$ & - Airways disease \\
\hline Scleroderma & $\begin{array}{l}\text { - Nonspecific interstitial } \\
\text { pneumonia } \\
\text { - Pulmonary } \\
\text { hypertension }\end{array}$ & $\begin{array}{l}\text { Usual interstitial } \\
\text { pneumonia }\end{array}$ \\
\hline $\begin{array}{l}\text { Systemic lupus } \\
\text { erythematosus }\end{array}$ & $\begin{array}{ll}\text { - } & \text { Pulmonary } \\
\text { hemorrhage } \\
\text { - } \\
\text { Diffuse alveolar } \\
\text { damage }\end{array}$ & $\begin{array}{ll}\text { - } & \text { Pulmonary } \\
\text { hypertension } \\
\text { - } & \text { Pulmonary } \\
\text { thromboembolism }\end{array}$ \\
\hline Myositis & $\begin{array}{l}\text { - Nonspecific interstitial } \\
\text { pneumonia } \\
\text { - Organizing } \\
\text { pneumonia }\end{array}$ & $\begin{array}{l}\text { Diffuse alveolar } \\
\text { damage }\end{array}$ \\
\hline $\begin{array}{l}\text { Sjögren } \\
\text { syndrome }\end{array}$ & $\begin{array}{l}\text { - Nonspecific interstitial } \\
\text { pneumonia } \\
\text { - Lymphoid interstitial } \\
\text { pneumonia } \\
\text { - Airways disease }\end{array}$ & \\
\hline $\begin{array}{l}\text { Mixed } \\
\text { connective } \\
\text { tissue disease }\end{array}$ & $\begin{array}{l}\text { - Nonspecific interstitial } \\
\text { pneumonia } \\
\text { - Usual interstitial } \\
\text { pneumonia }\end{array}$ & \\
\hline
\end{tabular}

\section{Key Point}

- The diagnosis of CTD is made predominantly using clinical and serologic findings. Imaging is important in the detection and characterization of lung disease, particularly given that pathology is not usually obtained.

\subsubsection{Rheumatoid Arthritis}

Most patients with rheumatoid arthritis (RA) have abnormalities on high-resolution chest CT; however they are commonly asymptomatic. The most common CT findings in the lungs include bronchial wall thickening (12-92\%), bronchial dilation $(30-40 \%)$, reticulation $(10-20 \%)$, ground-glass opacity (15-25\%), honeycombing (10\%), and consolidation (5\%) [9].

Airways disease appears to be the earliest manifestation of RA in the lung [10]. Bronchiectasis and air trapping are common findings [11]. There is a recognized association between RA and obliterative bronchiolitis (constrictive bronchiolitis) in which bronchioles are destroyed and replaced by scar tissue. The characteristic CT finding is mosaic perfusion with expiratory air trapping often associated with bronchial dilation. Follicular bronchiolitis is a second type of small airway disorder recognized in rheumatoid lung disease. The major CT finding is centrilobular nodules and areas of ground-glass opacity.

RA lung fibrosis is substantially more common in men than in women. The two most common patterns of lung fibrosis are UIP and NSIP [12]. Of all CTDs, RA is the most common to present with a UIP pattern. CT findings in interstitial pneumonia associated with RA are often indistinguishable from the idiopathic varieties; however other findings such as nodules, pulmonary arterial enlargement, or pleural abnormality may provide a clue to the underlying diagnosis. UIP and NSIP both typically demonstrate a subpleural and basilar distribution of findings. A confident diagnosis of UIP may be made when honeycombing and reticulation is present in this distribution. A confident diagnosis of NSIP may be made when there is an absence of honeycombing and subpleural sparing is present.

The new generation of biologic agents used to treat RA has resulted in a new array of potential pulmonary side effects. The most important of these is impaired immunity related to use of anti-TNF $\alpha$ antibodies (etanercept, infliximab, and adalimumab), which results in a substantially increased incidence of tuberculosis (sometimes disseminated or extra-articular) and nontuberculous mycobacterial infection. 
Low-dose methotrexate [13] may be associated with subacute hypersensitivity pneumonitis in $2-5 \%$ of cases. Preexisting radiographic evidence of interstitial lung disease probably predisposes to the development of methotrexate pneumonitis in patients with RA. Infections, such as pneumocystis pneumonia, are also a potential complication of therapy.

\subsubsection{Scleroderma (Progressive Systemic Sclerosis)}

Parenchymal lung involvement is very common in patients with scleroderma. Scleroderma is, in fact, the only CTD in which lung disease is a component of the defining criteria. At autopsy, the lungs are abnormal in at least $80 \%$ of cases. Lung fibrosis is the most common pattern of abnormality, with NSIP being much more common (>90\%) than UIP [14]. Pulmonary hypertension is also common, either as an isolated finding or in association with lung fibrosis. Pulmonary hypertension is particularly common in patients with limited scleroderma (CREST syndrome) [15]. Esophageal dilation is found in up to $80 \%$ of cases on CT.

CT findings in scleroderma reflect the dominant NSIP histology. Cellular NSIP presents with ground-glass opacity, often in a posterior and subpleural distribution. Fibrotic NSIP shows irregular reticulation and traction bronchiectasis as the predominant findings. Honeycombing is often absent, but when present, it is limited in extent [16]. Cellular and fibrotic NSIP often coexist, so findings may overlap. Subpleural sparing is particularly suggestive of a NSIP pattern.

The lung fibrosis associated with scleroderma is associated with a much better prognosis than that found in idiopathic lung fibrosis [17], most likely due in part to the predominant NSIP histology [18]. Fibrotic changes may stay stable for many years.

Pulmonary arterial hypertension usually causes enlargement of the main and proximal pulmonary arteries on chest radiograph or CT; however normal-sized pulmonary arteries do not exclude the diagnosis, and the presence of pericardial thickening or fluid in patients with scleroderma is also a strong predictor of echocardiographic pulmonary hypertension.

There is an increased prevalence of lung cancer in scleroderma, with relative risk of malignancy ranging from 1.8 to 6.5. Lung cancer in this condition often occurs in individuals with lung fibrosis.

\subsubsection{Systemic Lupus Erythematosus (SLE)}

Pleuritis is the most common pleuropulmonary manifestation of SLE, found in 40-60\% of patients, and may or may not be associated with pleural effusion.
Fibrotic interstitial lung disease [19] is less common in SLE than in the other CTDs. While pulmonary infection is said to be the most common pulmonary complication of SLE, acute pulmonary hemorrhage is also an important pulmonary complication of this condition, characterized radiologically by diffuse or patchy consolidation and ground-glass opacity [20].

Acute lupus pneumonitis is a poorly defined entity, characterized by a variable degree of respiratory impairment accompanied by focal or diffuse pulmonary consolidation, occurring in patients with lupus. It is now believed that most cases previously identified as lupus pneumonitis probably represented diffuse alveolar damage with or without pulmonary hemorrhage.

Other complications of lupus may include diaphragmatic dysfunction, pulmonary hypertension, and pulmonary thromboembolism [21], which may be related to antiphospholipid antibodies. Diaphragmatic dysfunction, thought to be due to a diaphragmatic myopathy, is manifested by reduced lung volumes ("shrinking lungs" with platelike atelectasis).

\section{Key Point}

- Fibrotic lung disease is much less common with SLE compared to other CTDs. Hemorrhage, diffuse alveolar damage, and pulmonary hypertension are more common findings.

\subsubsection{Polymyositis/Dermatomyositis (PM/DM)}

The presence of interstitial lung disease (ILD) in PM/DM correlates strongly with the presence of anti-Jo-1. About $50-70 \%$ of patients who are anti-Jo-1 positive have ILD, whereas the frequency of ILD falls to about $10 \%$ if antibodies are absent. ILD may antedate myositis in patients with anti-Jo-1 antibodies.

The most common pathologic findings are NSIP [22] and $\mathrm{OP}$, often occurring in combination. As with other CTDs, the occurrence of interstitial pneumonia may precede the development of clinical myositis.

Lung disease associated with PM/DM or with the antisynthetase syndrome, a closely related entity, is often associated with a characteristic CT appearance [23]. Confluent ground-glass opacity and consolidation in the lower lobes is superimposed on a background of traction bronchiectasis. This pattern reflects the characteristic histologic combination of organizing pneumonia and NSIP. On serial evaluation after treatment, consolidation often shows significant 
improvement or resolution; however fibrosis, manifested by reticulation and traction bronchiectasis, usually persists.

Diffuse alveolar damage is another pattern that may be seen in patients with PM/DM. Patients present with acute symptoms, as opposed to the subacute or chronic symptoms of NSIP and/or organizing pneumonia. Typical CT features of diffuse alveolar damage include symmetric bilateral ground-glass opacity and/or consolidation.

There is an increased risk for malignancy (especially for breast, lung, ovary, and stomach malignancies) that is concurrently diagnosed within 1 year follow-up in up to $20 \%$ of patients.

\subsubsection{Sjögren Syndrome}

CT provides substantial information regarding the pattern of pulmonary involvement in Sjögren syndrome. The patterns may be divided into airway abnormalities, interstitial fibrosis, pulmonary hypertension, and lymphoid interstitial pneumonia [24].

Airway-related abnormalities are common and consist of bronchial wall thickening, bronchiectasis, bronchiolectasis, and tree-in-bud opacities. Small airway disease may manifest by mosaic attenuation on inspiratory $\mathrm{CT}$ and air trapping on expiratory air trapping [25].

Nonspecific (NSIP) and lymphoid (LIP) interstitial pneumonia are the most common patterns of parenchymal lung disease. NSIP resembles that seen in scleroderma as above. LIP is characterized by ground-glass opacity due to the homogenous lymphocytic infiltration. Perilymphatic or centrilobular nodules may also be seen. Cysts measuring 5-30 $\mathrm{mm}$ may be seen in isolation or associated with other findings. These changes are ascribed to bronchiolar obstruction on the basis of lymphocytic wall infiltration. Cysts are helpful in distinguishing LIP from lymphoma.

Lymphoma should be suspected if consolidation, large nodules $(>1 \mathrm{~cm})$, mediastinal lymphadenopathy, or effusions are present. However, similar large "pseudo-alveolar" nodules can be found in combined amyloidosis and LIP. In contrast to other cystic lung diseases such as lymphangioleiomyomatosis, the cysts of LIP are fewer in number and show a peribronchovascular and lower lung predominance.

\subsubsection{Mixed Connective Tissue Disease}

Mixed connective tissue disease (MCTD) is an overlap syndrome that is a distinct clinicopathological entity. The principal characteristics are the presence of (1) features of SLE, scleroderma, and $\mathrm{PM} / \mathrm{DM}$, occurring together or evolving sequentially during observation and (2) antibodies to an extractable nuclear antigen (RNP).
Pulmonary involvement is common in MCTD with infiltrative lung disease present in as many as two thirds of patients. Many affected patients are asymptomatic. The pulmonary abnormalities resemble those seen in SLE, SS, and PM/DM. Thus, pleural thickening and pleural and pericardial effusions are common. Ground-glass attenuation is the commonest parenchymal abnormality [26]. The CT pattern corresponds most closely to NSIP. Less common findings include honeycombing, consolidation, and poorly defined centrilobular nodules.

Other important complications of MCTD include pulmonary arterial hypertension and esophageal dysmotility with sequelae of recurrent aspiration in the lungs.

\subsubsection{Interstitial Pneumonia with Autoimmune Features}

There is growing attention in the literature toward patients with interstitial lung disease that have some, but not all, features of a CTD. Multiple studies retrospectively identified subgroups of patients with one or multiple serological features of an autoimmune process in patients with histologically proven UIP or NSIP that were originally diagnosed as idiopathic because they did not fulfill the criteria of one of the stablished CTDs. Several terms have been suggested as a description for these subgroups including interstitial pneumonia with autoimmune features, undifferentiated CTD (UCTD), or lung-dominant CTD.

The term interstitial pneumonia with autoimmune features (IPAF) has been proposed for a subgroup of patients with findings suggestive but not diagnostic of a CTD [27]. To meet criteria for IPAF, patients must demonstrate specific features in two of the three following domains: (1) clinical, (2) serologic, and (3) anatomic. The anatomic domain may be satisfied by either typical patterns on CT or pathology. The CT patterns that are suggestive of CTD include nonspecific interstitial pneumonia (NSIP), organizing pneumonia (OP), an overlap of NSIP and OP, or lymphoid interstitial pneumonia. The presence of multi-compartmental findings is also suggestive including the combination of an interstitial pneumonia with any of the following: unexplained pleural effusion or thickening, pericardial effusion or thickening, airways disease, or pulmonary vasculopathy.

Key Point

- IPAF is a term used to describe patients who have some, but not all features, of a specific CTD. CT patterns that are suggestive of this diagnosis include NSIP, OP, an overlap of NSIP and OP, LIP, and multi-compartmental disease (e.g., interstitial pneumonia with pleural thickening). 


\subsubsection{Pulmonary Vasculitis/Diffuse Alveolar Hemorrhage}

The term "vasculitis" refers to disorders characterized by inflammation of blood vessel walls. Pathology includes the presence of leucocytes and fibrinoid necrosis in the vessel wall with consequent compromise of vessel integrity and hemorrhage, narrowing of vessel lumen with consequent downstream ischemia, and necrosis.

Classification of systemic vasculitis (Table 11.5) remains controversial. The current classification dated from the Chapel Hill Consensus Conference (CHCC) in 2012 continued to consider the predominant vascular size involved and distinguishes large-, medium-, or small-vessel vasculitis (LVV, MVV, or SVV, respectively). For the first time, ANCA (antineutrophil cytoplasmic antibody) was included in the classification.

Pulmonary involvement is typically seen with smallvessel vasculitis (SVV). SVV affects arterioles, venules, and capillaries. It is divided into antineutrophil cytoplasmic antibody (ANCA)-associated vasculitis (AAV) that includes microscopic polyangiitis, granulomatosis with polyangiitis (formerly Wegener), and eosinophilic granulomatosis with polyangiitis (formerly Churg-Strauss) [28]. The second group refers to immune complex SVV comprising among others antiglomerular basement membrane disease (Goodpasture) as the only one with regularly seen lung involvement. Behcet disease also belongs to immune complex-mediated vasculitis but involves variable vessel sizes (variable vessel vasculitis).

Clinical symptoms and radiologic signs [29] suggestive of pulmonary vasculitis include diffuse alveolar hemorrhage (DAH), acute glomerulonephritis, upper airway disease, lung nodules or cavitary nodules, mononeuritis multiplex, and palpable purpura [30]. Combined involvement of the lungs and kidneys by some of these diseases is also described as pulmonary-renal syndrome.

In addition to the abovementioned "primary pulmonary vasculitis," there is pulmonary vasculitis associated with connective tissue disorders such as rheumatoid arthritis, SLE, and systemic sclerosis as well as sarcoidosis and relapsing polychondritis. This type of vasculitis is considered "secondary vasculitis," though the differentiation between primary and secondary becomes increasing "blurry" as more and more etiologies for secondary vasculitis are discovered (e.g., drug-associated immune complex vasculitis). Nevertheless they all have in common the involvement of the small vessels ( $>100 \mu \mathrm{m}$ and $<1 \mathrm{~mm}$ ).

Diffuse alveolar hemorrhage (DAH) consisting of hemoptysis, diffuse alveolar infiltrates, and drop in hematocrit is a clinical syndrome and not a disease in itself. It occurs in all primary and secondary small-vessel vasculitides with capillaritis (GPA, EGPA, MPA, Henoch-Schonlein purpura,
Behcet, SLE, and Goodpasture). It has to be differentiated from other conditions such as bland pulmonary hemorrhage (e.g., coagulation disorders, mitral stenosis, drug-induced, etc.) and hemorrhage associated with diffuse alveolar damage (drug-induced, ARDS, bone marrow transplantation, or cocaine inhalation).

Key Point

- Small-vessel vasculitis is the most common to affect the lungs and primarily includes three diseases: microscopic polyangiitis, granulomatosis with polyangiitis (formerly Wegener), and eosinophilic granulomatosis with polyangiitis (formerly Churg-Strauss) [28]. Typical CT findings include multiple cavitating nodules and diffuse alveolar hemorrhage characterized by bilateral groundglass and consolidations.

\subsubsection{ANCA-Associated Granulomatous Vasculitis with Polyangiitis (GPA, Former Wegener's Disease)}

GPA is the most common of the AAV. It affects the sinuses, kidneys, and lungs resulting in the classic triad of symptoms comprising upper airway diseases (sinusitis, otitis, ulcerations, subglottis, and bronchial stenosis), lower respiratory tract involvement (clinically presenting as hemoptysis, chest pain, dyspnea, and cough), and glomerulonephritis (presenting as hematuria and azotemia). However, at initial presentation patients may not have the full spectrum (limited expressions of GPA); on the other hand, any part of the body may be affected in the course of disease. Females and males are affected equally and at any age (mostly age 40-55). Airway involvement is more frequent in men. The most common cause of death is renal failure. With treatment, the 24 months survival is $80 \%$. The factors initiating disease are unknown; current data support the involvement of (recurrent) infection for GPA. Up to $80 \%$ of patients are (in the course of disease) ANCA positive (mostly PR3-ANCA). Histologic findings include necrotizing granulomatous vasculitis of small to medium vessels without associated infection.

Though a number of attempts have been made to define diagnostic criteria (e.g., ACR criteria, CCHC nomenclature), it can be difficult to reliably distinguish GPA from MPA. Patients are usually included in the GPA category, if they are ANCA positive and if they have respiratory tract involvement supporting GPA, even though there is lack of identifiable evidence of systemic vasculitis (no renal involvement).

The most frequently seen pulmonary abnormalities are multiple nodules or masses of varying size with or without a CT halo sign (perinodular hemorrhage). They tend to involve 
Table 11.5 Classification of vasculitis according to the 2012 Chapel Hill Consensus conference (CHCC)

\begin{tabular}{|c|c|c|c|c|}
\hline & Vasculitis & Pulmonary-renal syndrome & Pulmonary hemorrhage & $\begin{array}{l}\text { Pulmonary } \\
\text { hypertension }\end{array}$ \\
\hline \multirow[t]{3}{*}{$\begin{array}{l}\text { Small-vessel } \\
\text { vasculitisANCA- } \\
\text { associated }\end{array}$} & $\begin{array}{l}\text { Granulomatous vasculitis with } \\
\text { polyangiitis(GPA)(former Wegener's) }\end{array}$ & $\begin{array}{l}\text { Pulmonary involvement } \\
90 \% \\
\text { Renal involvement } 80 \%\end{array}$ & In about $10 \%$ & - \\
\hline & $\begin{array}{l}\text { Eosinophilic granulomatous vasculitis } \\
\text { with polyangitisGPA(Church Strauss) }\end{array}$ & Up to $25 \%$ & Rare & - \\
\hline & Microscopic polyangiitis & $\begin{array}{l}\text { Frequently associated with } \\
\text { necrotizing } \\
\text { glomerulonephritis }\end{array}$ & Frequent & \\
\hline \multirow{3}{*}{$\begin{array}{l}\text { Small-vessel } \\
\text { vasculitisImmune } \\
\text { complex type }\end{array}$} & $\begin{array}{l}\text { Cryoglobulinemic } \\
\operatorname{IgA}(\text { Henoch-Schonlein })\end{array}$ & & & \\
\hline & $\begin{array}{l}\text { HUV(hypocomplementemic urticarial } \\
\text { vasculitis) }\end{array}$ & & & \\
\hline & Anti-GBM) & & $40-60 \%$ & \\
\hline $\begin{array}{l}\text { Medium-vessel } \\
\text { vasculitis (MVV) }\end{array}$ & Polyarteritis nodosa(PAN) & - & $\begin{array}{l}\text { Very rarely idiopathic, } \\
\text { associated with hepatitis } \\
\text { Bpart of RA, SLE }\end{array}$ & - \\
\hline \multirow{3}{*}{$\begin{array}{l}\text { Large-vessel vasculitis } \\
(\mathrm{LVV})\end{array}$} & Kawasaki syndrome & & & \\
\hline & Giant cell arteritis (GCA) & - & Rare, focal & Rare \\
\hline & Takayasu & - & Rare, focal & Rare \\
\hline \multirow{4}{*}{$\begin{array}{l}\text { Connective tissue } \\
\text { disorders }\end{array}$} & RA & - & Very rare, diffuse & Up to $60 \%$ \\
\hline & $\mathrm{SSc}$ & - & $\begin{array}{l}\text { Rare, diffusewith necr. } \\
\text { vasculitis }\end{array}$ & $10-60 \%$ \\
\hline & MCTD & - & Rare, diffuse & Up to $45 \%$ \\
\hline & SLE & Up to $60 \%$, late & $\begin{array}{l}\text { In } 4 \% \text {, diffuse(potentially } \\
\text { more frequent) }\end{array}$ & $5-45 \%$ \\
\hline
\end{tabular}

the subpleural regions; there is no predilection for upper or lower lung zones. Lesions can be as large as $10 \mathrm{~cm}$; however most are smaller. Lesions are often cavitary and have thick walls. Peripheral wedge-shaped areas of consolidation resemble infarcts and may also cavitate. Diffuse consolidation or ground-glass opacity is present in patients with pulmonary hemorrhage. Focal fibrotic changes reflect prior episodes of active disease, although diffuse lung fibrosis may occasionally be seen (mostly UIP pattern). Superinfection of cavitating nodules is not uncommon. A reverse halo sign may also be seen, reflecting organizing pneumonia. A key feature of GPA is the rapid temporal evolution of the nodules and airspace opacities.

In addition there may be a concentric thickening of tracheal or bronchial walls (in about $70 \%$ ) with a reduction in the luminal diameter and associated with atelectasis (seen in about $15 \%$ ). Bronchial abnormalities mainly involve the segmental and subsegmental bronchi. Involvement of the subglottic trachea is most typical.

The differential diagnosis depends upon the predominant manifestation. When nodules are the predominant feature, the differential diagnosis includes neoplasms (adenocarcinoma, metastases, and lymphoma) and certain infections (fungal and mycobacterial infections). In the setting of airspace consolidation, infection is also considered. When airway thickening is present, other considerations include amyloidosis, granulomatous disease, and relapsing polychondritis for airway disease.

\subsubsection{Eosinophilic Granulomatosis with Polyangiitis (EGPA, Former Churg-Strauss)}

Eosinophilic granulomatous disease with polyangiitis (formerly called Churg-Strauss syndrome) is caused by a SVV that almost exclusively occurs in patients with asthma and is characterized by a marked serum eosinophilia. Clinically, radiologically, and pathologically, it combines features of GPA and eosinophilic pneumonia (allergic granulomatosis and angiitis) [31]. Many other organs may be involved including the heart (up to $47 \%$ ), the skin (up to $40 \%$ ), and the musculoskeletal system (up to $50 \%$ ). Involvement of the peripheral nerves (in up to $75 \%$ ) is more frequent, while renal involvement and pulmonary hemorrhage are less common than in GPA.

Up to $30 \%$ are ANCA positive mostly MPO-ANCA; ANCA positivity is higher in active disease. Biopsy 
confirmation is recommended in case of ANCA negativity (in up to 40\%) and the presence of easily accessible lesions (e.g., skin). Histology demonstrates small-vessel (arteries and veins) vasculitis with eosinophilic infiltrates and vascular and extravascular granulomas. The 5-year survival is reported in up to $80 \%$ of patients; $50 \%$ of deaths are related to cardiac involvement. Clinically EGPA presents in three distinct phases (asthmatic, eosinophilic, and vasculitis phase), although these are not necessarily seen in that order. The asthmatic phase precedes the vasculitic phase by $8-10$ years.

Upper airway disease and pulmonary abnormalities are seen in up to $70 \%$ of patients with EGPA. The most common pulmonary findings include transient, multifocal, and non-segmental consolidations or ground-glass opacifications without zonal predilection [32]. The presence of (non-cavitating) small nodules or diffuse reticular opacities has also been reported. If located subpleurally, the consolidations mimic eosinophilic pneumonia. Pleural effusions are seen in about one third of patients due to cardiomyopathy or eosinophilic pleuritis. Interlobular thickening is seen in about $50 \%$ and is secondary to cardiogenic pulmonary edema, eosinophilic septal infiltration, or mild fibrosis.

Airway abnormalities are also an important thoracic manifestation and include wall thickening, dilatation, small centrilobular nodules, and mosaic perfusion. Bronchial wall thickening refers to eosinophilic and lymphocytic infiltration of the airway wall (the clinical symptom of asthma some time during disease course is obligatory for the diagnosis). Increased interlobular septa may reflect edema caused by cardiac and/or renal involvement or eosinophilic infiltration of the septa. Eosinophilic pleural effusion is seen in up to $50 \%$ of patients.

Airway changes consisting tree-in-bud, bronchial wall thickening and bronchial dilatation are likely to be related to asthma and are seen in almost patients; the wall thickening can also be caused by eosinophilic involvement.

The differential diagnosis includes chronic eosinophilic pneumonia, organizing pneumonia, and simple eosinophilic pneumonia (Löffler syndrome) in airspace disease. In airway-dominant disease, the list is longer and includes EAA, MPA, SLE, infectious bronchiolitis, and asthma.

\subsubsection{Microscopic Polyangiitis (MPA)}

Microscopic polyangiitis (MPA) is a systemic necrotizing small-vessel vasculitis without granulomatous inflammation. Clinically it is characterized by a long prodromal phase with weight loss and fever followed by a rapidly progressive glomerulonephritis. Microscopic polyangiitis is the most common cause of pulmonary-renal syndrome: rapidly progressive glomerulonephritis is seen in up to $90 \%$ and pulmonary involvement in up to $30-50 \%$. More than $75 \%$ of patients are ANCA positive in the course of disease, mostly MPO ANCA (in $35-65 \%$ ).

Microscopic polyangiitis is characterized by the combination of glomerulonephritis and diffuse alveolar hemorrhage (DAH). Imaging findings include patchy, bilateral, or diffuse airspace opacities. The opacity can show both features of consolidations and ground glass dependent on the amount of alveolar filling by blood. Typically DAH is more extensive in the perihilar areas, sparing lung apices, and the costophrenic angles. A halo surrounding a consolidation or nodule underlines the character of hemorrhage. During the phase of resorption, interlobular lines (crazy paving) may become more apparent.

Repeated hemorrhage leads to fibrosis with honeycombing, reticulation, and traction bronchiectasis. Interstitial lung disease may be seen in some patients, more frequently in MPA than in GPA.

\subsubsection{Antiglomerular Basement Membrane Disease (Anti-GBM Disease)}

Anti-GBM disease belongs to the group of immune complex SVV and is characterized by circulating antibodies against an antigen intrinsic to the glomerular basement membrane. It results in necrotizing glomerulonephritis with acute renal failure. The diagnosis is usually made via renal biopsy. Diffuse alveolar hemorrhage (DAH) occurs in about 40-60\%; isolated pulmonary involvement is extremely rare. The term Goodpasture syndrome is used for patients with glomerulonephritis and pulmonary hemorrhage irrespective of underlying cause, while the term Goodpasture disease is restricted to the combination of DAG, glomerulonephritis, and anti-GBM antibodies.

The serology comprises c-ANCA or p-ANCA positivity in 30\% and anti-basement membrane antibodies in $>90 \%$. Young men are more often affected than women (M:F $=9: 1)$, though it may also be seen in elderly women. With treatment the prognosis is good. Underlying pulmonary injury, e.g., by smoking or cocaine inhalation, is thought to predispose to pulmonary involvement. Recurrent episodes cause pulmonary fibrosis.

Imaging features consist of diffuse or patchy ground glass or consolidation, due to the alveolar hemorrhage, that typically resolve within days. Typically there is sparing of the subpleural space with predominance of the perihilar areas in the mid- and lower lung zones. Pleural effusion is uncommon. After recurrent episodes traction bronchiectasis, reticular opacities and honeycombing may evolve. 


\subsection{Miscellaneous Systemic Disorders}

\subsubsection{Inflammatory Bowel Disease}

Ulcerative colitis and Crohn's disease are associated with a wide variety of pulmonary complications [33]. Pulmonary complications may precede the diagnosis of inflammatory bowel disease or may occur years after the initial diagnosis and even after complete colectomy for ulcerative colitis. Indeed there is some suggestion that pulmonary complications may be more common after surgical treatment, perhaps because anti-inflammatory treatment is withdrawn. Both Crohn's disease and ulcerative colitis can be associated with tracheobronchitis and airway stenosis [34]. Bronchiectasis and bronchial wall thickening are also common. Parenchymal abnormalities associated with inflammatory bowel disease include organizing pneumonia, pulmonary hemorrhage, and granulomatous infiltration in Crohn's disease.

\subsubsection{Amyloidosis and Light Chain Deposition Disease}

Amyloidosis and light chain deposition disease are rare disorders characterized by the extracellular deposition of proteins in one or more organs. They both share clinical, radiographic, and pathologic features. The main difference between these two entities is the Congo red staining and fibrillar structure on electron microscopy of amyloidosis. Both entities may be associated with a plasma cell dyscrasia.

Three radiographic manifestations of amyloidosis are described: nodular parenchymal, diffuse alveolar septal, and tracheobronchial [35]. The nodular parenchymal form presents radiographically as one or more solid lung nodules, often found incidentally. These may be confused with malignancy, particularly when spiculated borders are present. A slow growth rate is typical, and calcification may be present. The diffuse alveolar septal form is characterized by the presence of widespread deposits throughout the lungs. The most common findings are small nodules (typically in a perilymphatic distribution), consolidation, ground-glass opacity, and reticulation. The presence of calcification associated with these abnormalities may be particularly suggestive. The tracheobronchial form shows extensive thickening of the trachea and/or bronchi with or without calcification.

The imaging findings of light chain deposition disease are less well described. There are two types: nodular and diffuse [36]. The nodular type presents with scattered solid nodules, often associated with cysts. The nodules are typically located within or adjacent to the wall of the cysts. The diffuse type may show diffuse small nodules, resembling the diffuse alveolar septal type of amyloidosis.

\subsubsection{Erdheim-Chester Disease}

Erdheim-Chester disease is an infiltrative disorder in which non-Langerhans' cell histiocytes are found in one or more organ systems. The primary organs affected include bones, brain, kidneys, and the cardiovascular system. Middle-aged males are most commonly affected. While pathology is helpful in excluding lymphoproliferative malignancies, the pathologic findings may be nonspecific; thus typical radiographic features are a key to appropriate diagnosis. Characteristic imaging findings [37] in the chest include periadventitial aortic soft tissue thickening. This thickening may involve the aorta and its main branches diffusely, giving rise to the term "coating" of the aorta. The most common lung finding seen is smooth interlobular septal thickening, resembling pulmonary edema. The most characteristic finding outside of the chest is circumferential perinephric soft tissue, resembling lymphoma.

\subsubsection{IgG4-Related Sclerosing Disease}

IgG4-related sclerosing disease is a disorder originally thought to be isolated to the pancreas and previously called lymphoplasmacytic sclerosing pancreatitis. It is now recognized as a systemic order associated with IgG4 plasma cells and fibrosclerosis in multiple organ systems. The primary organs involved include the pancreas, hepatobiliary system, salivary glands, and lymph nodes. The findings in the chest are variable and may include nodules, lymphadenopathy, airway thickening, and pleural abnormalities [38]. Also, it is possible that IgG4-related sclerosing disease may account for a proportion of cases of idiopathic interstitial pneumonias.

\subsection{Conclusions}

Systemic disorders demonstrate a wide variety of manifestations in the chest. Imaging, and in particular computed tomography, plays a critical role in the diagnosis of these disorders, however the imaging findings must be correlated with the typical clinical manifestations affecting multiple organ systems. An in-depth knowledge of both typical and atypical imaging features is critical in the multidisciplinary diagnosis and follow-up of patients with these diseases. 


\section{Take-Home Messages}

- The classic imaging features of sarcoidosis include (1) clustered nodules in the peribronchovascular and subpleural interstitium (a perilymphatic distribution), (2) symmetric bilateral hilar and mediastinal lymphadenopathy, and/or (3) peribronchovascular and upper lung fibrosis.

- Diagnosis in CTDs is made predominantly using clinical and serologic criteria; however imaging is critical in determining the predominant pattern of imaging present.

- The most typical patterns of lung disease seen with CTD include nonspecific interstitial pneumonia, organizing pneumonia, and lymphoid interstitial pneumonia. These patterns not infrequently overlap.

- Vasculitis is classified by the size of vessels involved, and lung disease is most commonly seen with small-vessel vasculitis including granulomatosis with polyangiitis, microscopic polyangiitis, and eosinophilic granulomatosis with polyangiitis.

- The most typical CT appearances of vasculitis include multiple cavitary nodules of varying sizes and alveolar hemorrhage characterized by bilateral ground-glass opacity and consolidation.

\section{References}

1. Valeyre D, Prasse A, Nunes H, Uzunhan Y, Brillet P-Y, MüllerQuernheim J. Sarcoidosis. Lancet. 2014;383:1155-67.

2. Spagnolo P, Sverzellati N, Wells AU, Hansell DM. Imaging aspects of the diagnosis of sarcoidosis. Eur Radiol. 2014;24:807-16. Springer Berlin Heidelberg.

3. Criado E, Sánchez M, Ramírez J, et al. Pulmonary sarcoidosis: typical and atypical manifestations at high-resolution CT with pathologic correlation. Radiographics. 2010;30:1567-86.

4. Treglia G, Annunziata S, Sobic-Saranovic D, Bertagna F, Caldarella C, Giovanella L. The role of 18F-FDG-PET and PET/CT in patients with sarcoidosis: an updated evidence-based review. Acad Radiol. 2014:21:675-84.

5. Walsh SL, Wells AU, Sverzellati N, et al. An integrated clinicoradiological staging system for pulmonary sarcoidosis: a case-cohort study. Lancet Respir Med. 2014;2:123-30.

6. Fischer A, Bois du R. Interstitial lung disease in connective tissue disorders. Lancet. 2012;380:689-98.

7. Travis WD, Costabel U, Hansell DM, et al. An official American Thoracic Society/European Respiratory Society statement: update of the international multidisciplinary classification of the idiopathic interstitial pneumonias. Am J Respir Crit Care Med. 2013;188:73348. American Thoracic Society.

8. Kim EA, Lee KS, Johkoh T, et al. Interstitial lung diseases associated with collagen vascular diseases: radiologic and histopathologic findings. Radiographics. 2002;22:S151-65.
9. Mori S, Cho I, Koga Y, Sugimoto M. Comparison of pulmonary abnormalities on high-resolution computed tomography in patients with early versus longstanding rheumatoid arthritis. J Rheumatol. 2008;35:1513-21.

10. Remy-Jardin M, Remy J, Cortet B, Mauri F, Delcambre B. Lung changes in rheumatoid arthritis: CT findings. Radiology. 1994; 193:375-82.

11. Perez T, Remy-Jardin M, Cortet B. Airways involvement in rheumatoid arthritis: clinical, functional, and HRCT findings. Am J Respir Crit Care Med. 1998;157:1658-65. American Thoracic Society, New York, NY.

12. Tanaka N, Kim JS, Newell JD, et al. Rheumatoid arthritis-related lung diseases: CT findings. Radiology. 2004;232:81-91.

13. Hilliquin P, Renoux M, Perrot S, Puéchal X, Menkès CJ. Occurrence of pulmonary complications during methotrexate therapy in rheumatoid arthritis. Br J Rheumatol. 1996;35:441-5.

14. Kim DS, Yoo B, Lee JS, et al. The major histopathologic pattern of pulmonary fibrosis in scleroderma is nonspecific interstitial pneumonia. Sarcoidosis Vasc Diffuse Lung Dis. 2002;19:121-7.

15. Fagan KA, Badesch DB. Pulmonary hypertension associated with connective tissue disease. Prog Cardiovasc Dis. 2002;45:225-34.

16. Remy-Jardin M, Remy J, Wallaert B, Bataille D, Hatron PY. Pulmonary involvement in progressive systemic sclerosis: sequential evaluation with CT, pulmonary function tests, and bronchoalveolar lavage. Radiology. 1993;188:499-506.

17. Wells AU, Cullinan P, Hansell DM, et al. Fibrosing alveolitis associated with systemic sclerosis has a better prognosis than lone cryptogenic fibrosing alveolitis. Am J Respir Crit Care Med. 1994;149:1583-90. American Public Health Association.

18. Bouros D, Wells AU, Nicholson AG, et al. Histopathologic subsets of fibrosing alveolitis in patients with systemic sclerosis and their relationship to outcome. Am J Respir Crit Care Med. 2002;165:1581-6. American Thoracic Society.

19. Fenlon HM, Doran M, Sant SM, Breatnach E. High-resolution chest CT in systemic lupus erythematosus. AJR Am J Roentgenol. 1996:166:301-7. American Public Health Association.

20. Wiedemann HP, Matthay RA. Pulmonary manifestations of systemic lupus erythematosus. J Thorac Imaging. 1992;7:1-18.

21. Swigris JJ, Fischer A, Gillis J, Gilles J, Meehan RT, Brown KK. Pulmonary and thrombotic manifestations of systemic lupus erythematosus. Chest. 2008;133:271-80.

22. Arakawa H, Yamada H, Kurihara Y, et al. Nonspecific interstitial pneumonia associated with polymyositis and dermatomyositis: serial high-resolution $\mathrm{CT}$ findings and functional correlation. Chest. 2003;123:1096-103.

23. Fischer A, Swigris JJ, Bois du RM, et al. Anti-synthetase syndrome in ANA and anti-Jo-1 negative patients presenting with idiopathic interstitial pneumonia. Respir Med. 2009;103:1719-24.

24. Taouli B, Brauner MW, Mourey I, Lemouchi D, Grenier PA. Thinsection chest CT findings of primary Sjögren's syndrome: correlation with pulmonary function. Eur Radiol. 2002;12:1504-11. Springer-Verlag.

25. Franquet T, Giménez A, Monill JM, Díaz C, Geli C. Primary Sjögren's syndrome and associated lung disease: CT findings in 50 patients. AJR Am J Roentgenol. 1997;169:655-8. American Public Health Association.

26. Saito Y, Terada M, Takada T, et al. Pulmonary involvement in mixed connective tissue disease: comparison with other collagen vascular diseases using high resolution CT. J Comput Assist Tomogr. 2002;26:349-57.

27. Fischer A, Antoniou KM, Brown KK, et al. An official European Respiratory Society/American Thoracic Society research state- 
ment: interstitial pneumonia with autoimmune features. Eur Respir J. 2015;46:976-87.

28. Khan I, Watts RA. Classification of ANCA-associated vasculitis. Curr Rheumatol Rep. 2013;15:383. Springer US.

29. Chung MP, Yi CA, Lee HY, Han J, Lee KS. Imaging of pulmonary vasculitis. Radiology. 2010;255:322-41. Radiological Society of North America, Inc.

30. Marten K, Schnyder P, Schirg E, Prokop M, Rummeny EJ, Engelke C. Pattern-based differential diagnosis in pulmonary vasculitis using volumetric CT. AJR Am J Roentgenol. 2005;184:720-33.

31. Specks U, DeRemee RA. Granulomatous vasculitis. Wegener's granulomatosis and Churg-Strauss syndrome. Rheum Dis Clin N Am. 1990;16:377-97.

32. Worthy SA, Müller NL, Hansell DM, Flower CD. Churg-Strauss syndrome: the spectrum of pulmonary CT findings in 17 patients. AJR Am J Roentgenol. 1998;170:297-300. American Public Health Association.
33. Camus P, Piard F, Ashcroft T, Gal AA, Colby TV. The lung in inflammatory bowel disease. Medicine (Baltimore). 1993;72:151-83.

34. Garg K, Lynch DA, Newell JD. Inflammatory airways disease in ulcerative colitis: CT and high-resolution CT features. J Thorac Imaging. 1993;8:159-63.

35. Urban BA, Fishman EK, Goldman SM, et al. CT evaluation of amyloidosis: spectrum of disease. Radiographics. 1993;13:1295-308.

36. Bhargava P, Rushin JM, Rusnock EJ, et al. Pulmonary light chain deposition disease: report of five cases and review of the literature. Am J Surg Pathol. 2007;31:267-76.

37. Brun A-L, Touitou-Gottenberg D, Haroche J, et al. ErdheimChester disease: CT findings of thoracic involvement. Eur Radiol. 2010;20:2579-87.

38. Ryu JH, Sekiguchi H, Yi ES. Pulmonary manifestations of immunoglobulin G4-related sclerosing disease. Eur Respir J. 2012;39:1806. European Respiratory Society.

Open Access This chapter is licensed under the terms of the Creative Commons Attribution 4.0 International License (http://creativecommons. org/licenses/by/4.0/), which permits use, sharing, adaptation, distribution and reproduction in any medium or format, as long as you give appropriate credit to the original author(s) and the source, provide a link to the Creative Commons license and indicate if changes were made.

The images or other third party material in this chapter are included in the chapter's Creative Commons license, unless indicated otherwise in a credit line to the material. If material is not included in the chapter's Creative Commons license and your intended use is not permitted by statutory regulation or exceeds the permitted use, you will need to obtain permission directly from the copyright holder. 